\title{
Three new genera of Oriental scuttle flies (Diptera: Phoridae)
}

\author{
R. Henry L. DisneY \\ Department of Zoology, University of Cambridge, Cambridge CB2 3EJ, England; e-mail: rhld2@hermes.cam.ac.uk
}

Abstract: The Oriental Hippaphora viklundi gen. nov. sp. nov. female, Obscurcaudaphora maculafemoralis gen. nov. sp. nov. male and Tendcornphora microgenitalis gen. nov. sp male, are described.

Key words: Diptera, Phoridae, new genera, Oriental Region

\section{INTRODUCTION}

The late Dr Bert Viklund (of the Swedish Museum of Natural History) sent me some odd scuttle flies collected by himself and colleagues in the Oriental Region. Four proved to be new genera. On learning of his untimely death in 2014 I selected the oddest of them, Erinacephora viklundi Disney (2015), and submitted its description as a tribute to him in recognition of his contributions to entomology. In this paper I describe the other three new genera.

\section{METHODS}

The specimens were collected in traps and preserved in dilute ethanol. I then mounted these on slides in Berlese Fluid (Disney 2001).

\section{DESCRIPTIONS OF THE NEW GENERA}

The holotypes have been deposited in the Swedish Museum of Natural History (SMNH).

The most recent keys (the males and females being treated separately) to genera of Phoridae for the Australasian and Oriental Regions are those of Disney (1994). Several genera have been added since and it is indicated in each case how they ran down in these keys.

\section{Hippaphora gen. nov.}

Diagnosis. Dorsoventrally flattened and only lightly sclerotised. Head much broader than long, without a median furrow, with numerous strong hairs above and below with some increasingly more bristle like laterally and with a pair strong supra-antennal bristles. The eyes reduced to a few ommatidia and ocelli lacking. Postpedicels subglobose and palps long and slender. Proboscis with the labium a greatly elongated but narrow basiproboscis and a similar distiproboscis. Thorax much wider than long, with fine hairs on scutum and some bristles on the reduced mesopleuron. Scutellum lacking. Mid and hind tibiae with dorsal hair palisades. Mid and hind tarsi with posterodorsal hair palisades on segments 1-4 but front tarsi lack these. Wings with a hairy costa with a terminal bristle and membrane reduced to a narrow strip in basal two thirds. Haltere with a narrow tapered knob. Abdomen without tergites but with numerous fine hairs.

In the key to genera for females (Disney 1994) it readily runs to couplet 67, where lead 1 is for Rhynchomicropteron Annandale 1912, which differs in the much narrower head and thorax and which are both normally sclerotised. If one follows lead 2 one proceeds to couplet 71 
where it fails to key out. If, however, one proceeds to couplet 73 and runs on to couplet 75 again neither lead applies. Subsequently described genera do not run to these couplets. Unless the unknown male proves to be a known genus then this female is incompatible with any known genus.

Etymology. Named after the collector of the genotype, Heikki Hippa.

\section{Hippaphora viklundi sp. nov.}

(Figs 1-8)

Female. Fig. 1 depicts the whole fly from above. The head enlarged as Fig. 2 and from below as in Fig. 3. The postpedicels as in Fig. 4. The eyes are reduced to just a few ommatidia (Fig. 5). Thorax with fine hairs, an intra-alar bristle, 3 notopleural bristles, 3 bristles on the reduced mesopleuron and some bristles on propleuron. Wing and haltere as in Fig. 6. The abdominal hairs are fine (Fig. 7). The hind femora as in Fig. 8.

Etymology. Named after the late Bert Viklund, who sent me the specimen of the holotype.

Material. Holotype $\circ$, Indonesia, Sumatra, Sumatera Utara, Semangat Gunung, 1200 m, Malaise trap in jungle, 14.3.1992, Heikki Hippa (SMNH, 20-19).

\section{Obscurcaudaphora gen. nov.}

Diagnosis. With a full set of frontal bristles, ocelli present, subglobose postpedicels, mesopleuron bare and with a mesopleural furrow, 3 bristles on notopleuron, length of cerci greater than breadth, anal tube shorter than length of epandrium, mid and hind tibiae lack preapical bristles and dorsal hair palisades, wing with tip of subcosta fusing with vein 1 , vein 3 without a basal hair, costal index more than 0.5 and axillary ridge lacks bristles. In the key to genera for males (Disney 1994) it will run to couplet 189. The lead 1 option differs in the number of scutellar hairs and bristles and its hypopygium is quite different. Taking lead 2 one proceeds to couplet 216 , where it differs by having a complete set of frontal bristles. The hypopygium, the notched front basitarsus, palps and hypopygium immediately distinguish it.

Etymology. Named after the unusually dusky hypopygium of the male.

\section{Obscurcaudaphora maculafemoralis sp. nov.}

(Figs 9-18)

Male. Frons as in Fig. 10. Postpedicels, palps and proboscis as in Fig. 9. Hypopygium as in Figs 11-13. The structure labelled X in Fig. 13 is interpreted as sternite 10. Front leg as in Fig. 16, with its basitarsus as in Figs 14 and 15. Hind femur and tibia as in Fig. 17. Wing (Fig. 18) $1.6 \mathrm{~mm}$ long, costal index 0.55 , costal ratios $0.67: 1$, costal cilia $0.04 \mathrm{~mm}$ long. Haltere knob brown.

Etymology. Named after the dark patches on the front femora.

Material. Holotype $\sigma^{\lambda}$, Malaysia, Sabah, Tawau, Maliau Basin, $800 \mathrm{~m}$ from Nepenthes Camp, Heath Forest, 0443'17.0"N, 116 52'46.6"E, 1047m m.a.o., 8-15 Dec 2007. Malaise trap, B. Viklund and N. Jönsson (SMNH, 20-17). ${ }^{\circ}$

\section{Tendcornphora gen. nov.}

Diagnosis. Frons without bristles or median furrow, postpedicels greatly elongated with a small apical arista, palps and proboscis small, scutellum almost as large as scutum, mesopleuron bare and without a median furrow, hypopygium unusually small, mid tibia without pre-apical bristles, hind tibia without a dorsal hair palsade but with a row of posterodorsal long bristles, costal index less than 0.25 , vein 3 unforked. In the key to males 


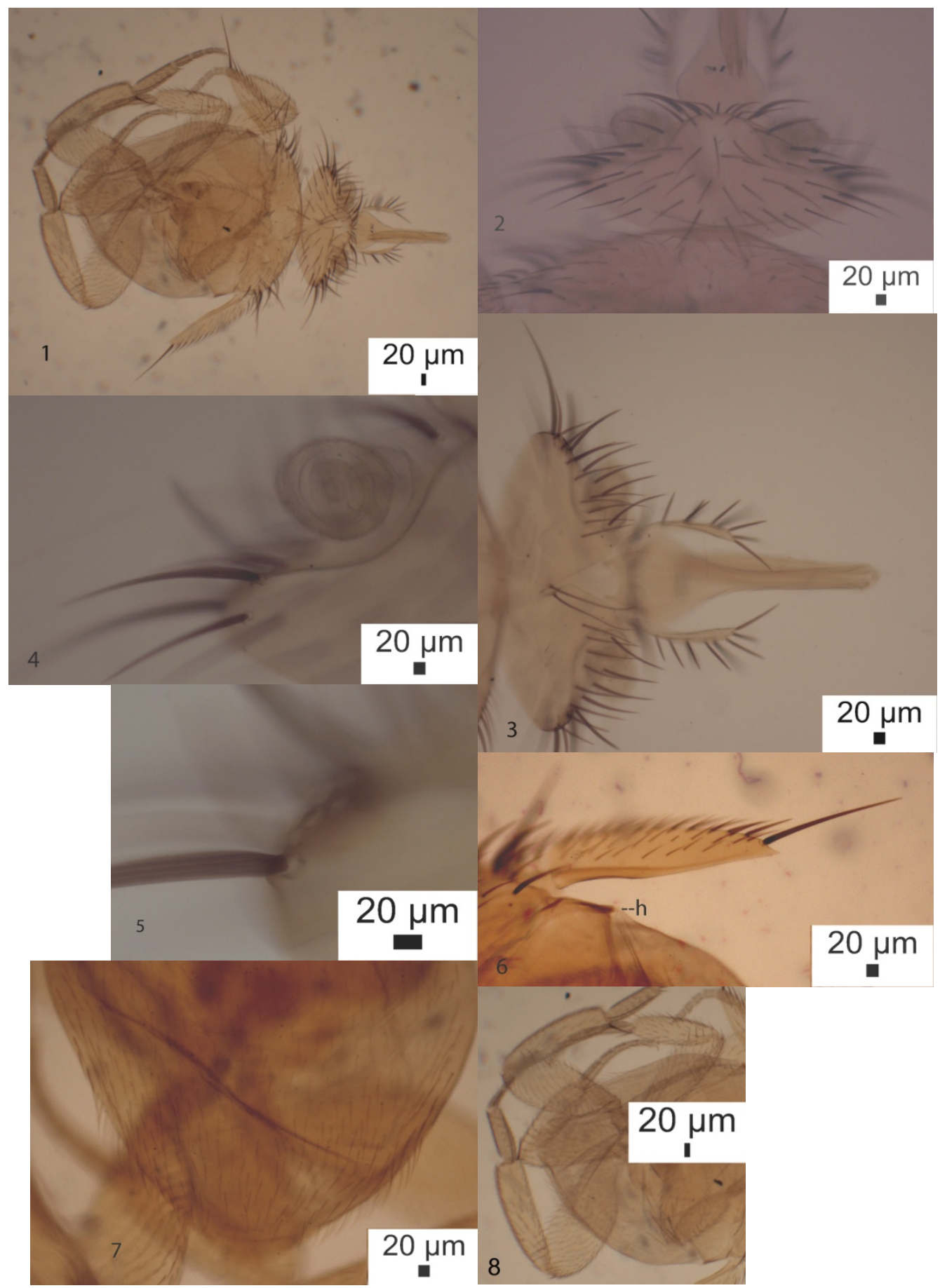

Figs 1-8. Hippaphora viklundi sp. nov. female. 1 - dorsal view; 2 - dorsal view of head; 3 - ventral view of head; 4 postpedicel; 5 - eye; 6 - wing plus haltere (h); 7 - hairs of dorsal face of abdomen; 8 - hind femora. 

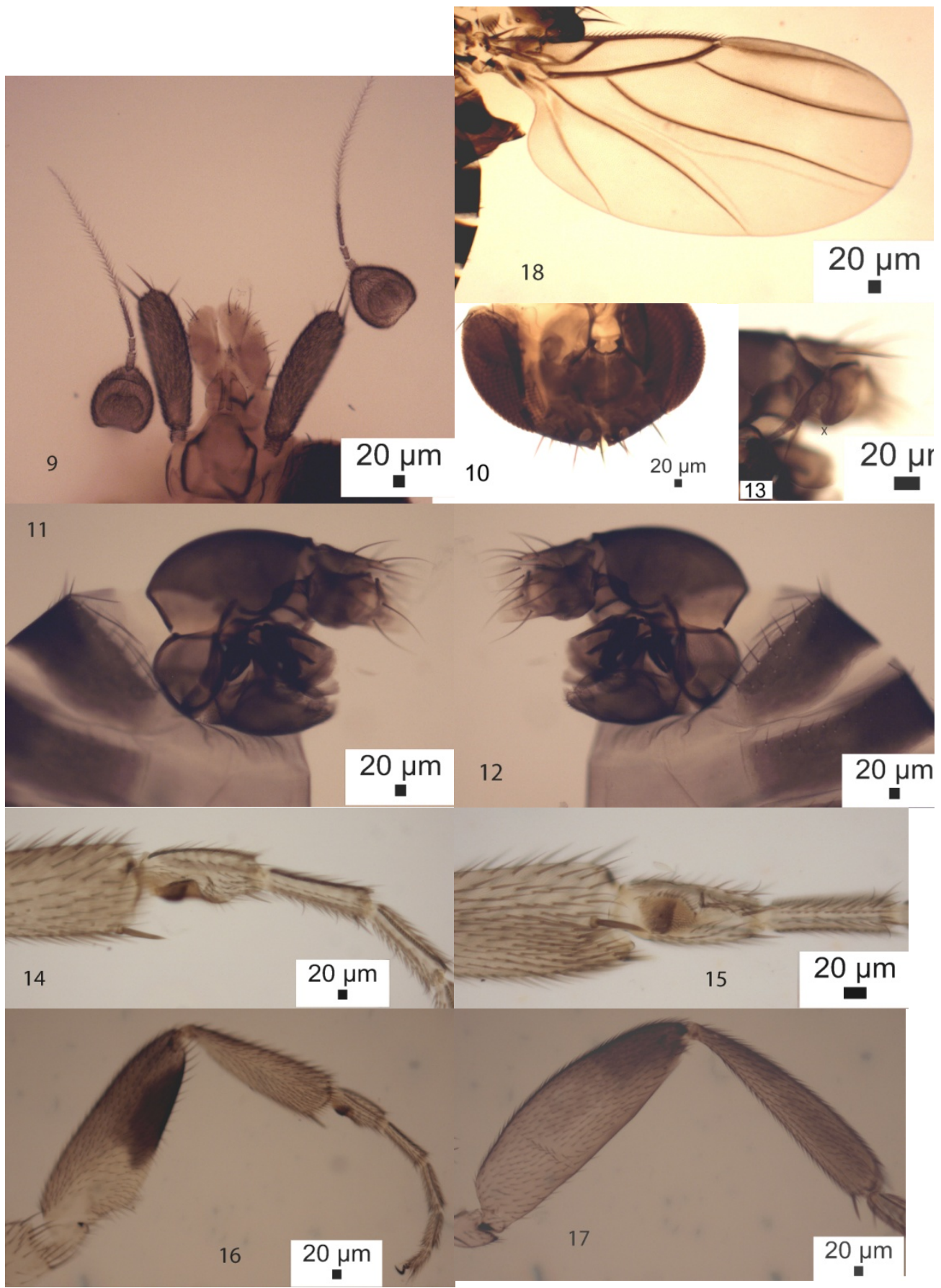

Figs 9-18. Obscurcaudaphora maculafemoralis sp. nov. male. 9- postpedicels, palps and proboscis; 10 - frons; 11-13 - hypopygium: 11 - left face; 12 - right face; 13 - left face of sternite 10 (x); 14-15 - anterior and posterior face of front basitarsus; 16 - front leg; 17 - hind femur and tibia; 18 - wing. 
(Disney 1994) it readily runs to couplet 15 , where lead 1 runs on to two genera that are clearly different. Lead 2 takes one to couplet 35, lead 1 to Leptilla Borgmeier 1963. However, although its costa is also exceptionally short, its postpedicel is broad basally before it starts to taper before this distal portion which has long hairs, its palp is 4 times as long as its breadth, the frons has bristles and its hypopygium is clearly different.

Etymology. Named after the long drawn out (stretched) postpedicels of the male antennae.

\section{Tendcornphora microgenitalis sp. nov.}

(Figs 19-28)

Male. Head as in Fig. 19. Postpedicels as in Figs 20 and 21. Palps brown, only about as long as wide and with 1-2 small hairs only. Scutellum as in Fig. 22. Abdominal tergites as in Fig. 23. Hypopygium as in Figs 24 and 25. Front leg as in Fig. 26. Hind femur, tibia and basitarsus as in Fig. 27. Wing as in Fig. 28, $1.4 \mathrm{~mm}$ long, costal index 0.23, costal cilia 0.07 $\mathrm{mm}$ long. Haltere with pale stem and brown knob.

Etymology. Named after the unusually small male hypopygium.

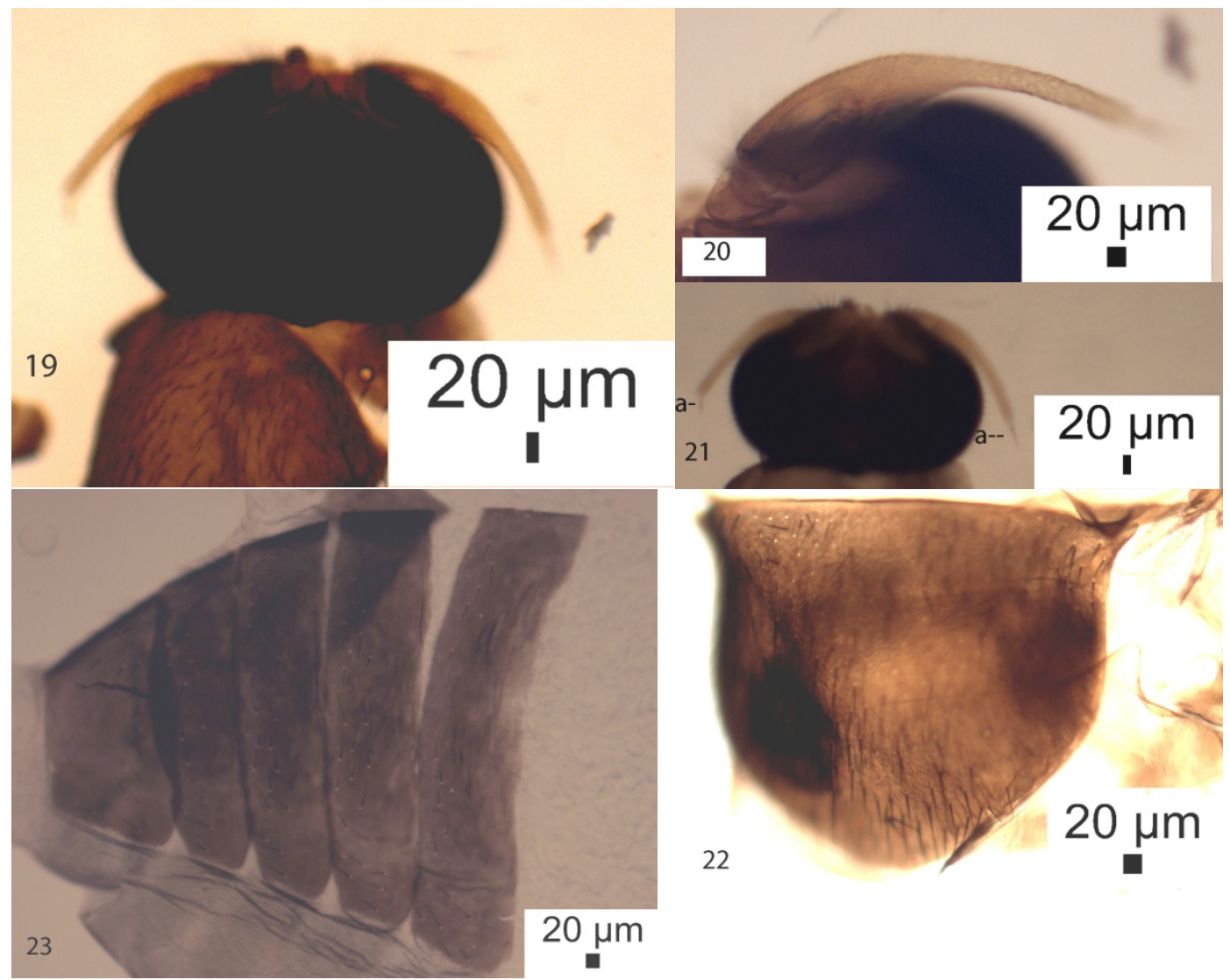

Figs 19-23. Tendcornphora microgenitalis sp. nov. male. 19 - head; 20 - postpedicels; 21 - tips of postpedicels; 22 scutellum; 23 - abdominal tergites. 
Material. Holotype $\widehat{\partial}$, Malaysia, Sabah, Tawau, Maliau Basin, stream passing Riparian Nature Trail, 04²4'32.5"N, 116 58'14.2"E, 244 m.a.o., 6 Dec 2007, light trap 22W black light, B. Viklund and N. Jönsson (SMNH, 20-17).

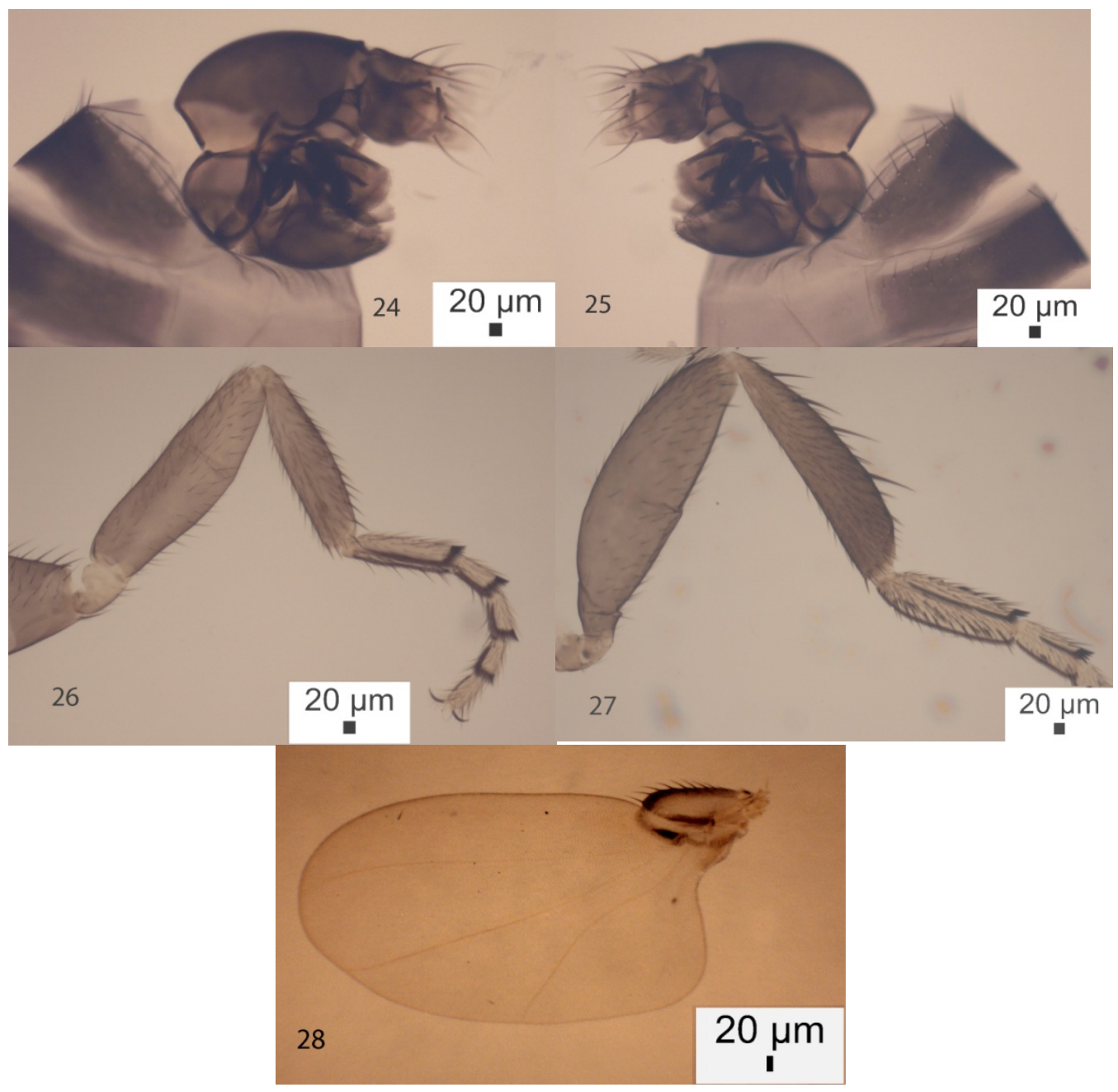

Figs 24-28. Tendcornphora microgenitalis sp. nov. male: 24 - left face of hypopygium; 25 - right face of hypopygium; 26 - front leg; 27 - hind femur, tibia and first two tarsal segments; 28 - wing.

\section{DISCUSSION}

All three genera described above are very distinctive. However they add to the number of genera still only known in one sex. In the past greatly sexually dimorphic genera have had the two sexes assigned to different genera before being eventually linked, and one genus has then been synonymised with the other. Indeed with the Termitoxeniinae the females were originally assigned to a different family before the males were found to have been assigned to the Metopininae of the Phoridae (Disney \& Cumming 1992). There is therefore a risk that at least one of the above genera may have already been described from its opposite sex. 


\section{REFERENCES}

ANNANDALE N. 1912. Description of a micropterous fly of the family Phoridae associated with ants. Spolia Zeylanica, Colombo 8: 85-89.

Borgmeier T. 1963. New or little known phorid flies from Australia (Dipt. Phoridae). Anais da Academia Brasileira de Ciências, Rio de Janeiro 35: 109-124.

Disney R. H. L. 1994. Scuttle Flies: The Phoridae (London: Chapman \& Hall). [Archived by Springer Book Archives - https://www.springer.com]

DISNEY R. H. L. 2001. The preservation of small Diptera. Entomologists's Monthly Magazine 137: 155-159.

DisNEY R. H. L. 2015. A new genus of scuttle fly (Diptera: Phoridae) from Malaysia. Entomologist's Monthly Magazine 151: 161-164.

Disney R. H. L. \& CUMming M. S. 1992. Abolition of the Alamirinae and ultimate rejection of Wasmann's theory of hermaphroditism in Termitoxeniinae (Diptera, Phoridae). Bonner zoologische Beiträge 43: 145-154.

\section{STRESZCZENIE}

\section{[Trzy nowe rodzaje zadrowatych (Diptera, Phoridae) z regionu orientalnego]}

W pracy zostały opisane trzy rodzaje nowe dla nauki i należące do tych rodzajów trzy gatunki orientalnych zadrowatych: Hippaphora viklundi gen. nov. sp. nov. (samica), Obscurcaudaphora maculafemoralis gen. nov. sp. nov. (samiec) i Tendcornphora microgenitalis gen. nov. sp (samiec). 